\title{
Quality of life of persons after total knee replacement surgery
}

\author{
Soo-Hyun Leem ${ }^{a}$, Byounghee Lee ${ }^{b}$, EunJung Chung ${ }^{c}$, Jiyeon Lee ${ }^{d}$, Jung-Hee Kim ${ }^{c}$ \\ ${ }^{a}$ Department of Physical Therapy, Shamyook Medical Center, Seoul, Republic of Korea \\ ${ }^{b}$ Department of Physical Therapy, College of Health Science and Social Welfare, Sahmyook University, Seoul, Republic of Korea \\ 'Department of Physical Therapy, Andong Science College, Andong, Republic of Korea \\ ${ }^{\mathrm{d} D e p a r t m e n t}$ of Physical Therapy, Asan Medical Center, Seoul, Republic of Korea
}

Objective: The objective of this study was to investigate the differences in the quality of life between two groups of patients who received or did not receive total knee replacement (TKR) surgery after being diagnosed with knee osteoarthritis (OA), and to investigate changes in the quality of life for persons who had TKR surgery.

Design: Cross-sectional study.

Methods: The subjects were randomized into a surgery group $(\mathrm{n}=70)$ and a non-surgery group $(\mathrm{n}=65)$. Subjects were selected from individuals diagnosed with knee OA from Himchan Hospital in Seoul, South Korea. Their sex, age, weight, height, body mass index, unilateral or bilateral, and quality of life were evaluated. Changes in the quality of life was measured using the Short Form-36 Health Survey (SF-36). Seventy out of 135 patients had TKR surgery, and their quality of life was evaluated at 6 months and 12 months after the surgery.

Results: SF-36 scores were significantly improved at 6 months and 12 months after the surgery compared to the scores before the surgery $(p<0.05)$. Also, the comparison between 6 and 12 months after surgery showed that the Vitality and Social Function scores in the SF-36 were significantly increased $(p<0.05)$.

Conclusions: The findings of this study showed that TKR surgery has a positive effect on the quality of life for persons with knee $\mathrm{OA}$ as a therapeutic intervention.

Key Words: Arthroplasty, Function, Knee, Osteoarthritis, Quality of life, Therapeutic intervention

\section{Introduction}

Knee osteoarthritis (OA) is the most common joint disease in the world [1]. Knee OA causes pain, stiffness, decreased range of motion, functional limitation and disability, and its incidence rate is gradually rising with an increase in the elderly population. Knee OA brings individual and societal consequences in terms of musculoskeletal pain, disability and socioeconomic costs [2,3]. There is a high correlation between pain and limited functional activities that require the use of the knee in persons with OA. Total knee replacement (TKR) surgery is one of the most successful procedures and is widely performed on patients who have late-stage knee OA. TKR is aimed at reducing pain and improving physical function in those with knee OA $[4,5]$. Persons with TKR are characterized by a slight increase in function [6], with a decrease in knee joint extension strength, knee joint movement, functional performance, and complaints of activity of daily living performance [7,8]. Although TKR surgery is generally effective in terms of pain reduction and correcting joint alignment, patients do not always achieve a return to full function and may be left with limitations in mobility and other activities of daily living [9]. To assess the effect of TKR, a variety of analysis programs have been introduced [10], and many components including pain [11], function [1,12], range of motion [13], muscle

Received: 2 September, 2019 Revised: 25 September, 2019 Accepted: 25 September, 2019

Corresponding author: Jung-Hee Kim (ORCID https://orcid.org/0000-0001-9766-6068)

Department of Physical Therapy, Andong Science College, 189 Seoseon-gil, Seohu-myeon, Andong, Republic of Korea Tel: 82-54-851-3559 Fax: 82-954-852-9907 E-mail: mirrorneuron98@gmail.com

(a) This is an Open-Access article distributed under the terms of the Creative Commons Attribution Non-Commercial License (http://creativecommons.org/licenses/ by-nc/4.0) which permits unrestricted non-commercial use, distribution, and reproduction in any medium, provided the original work is properly cited.

Copyright (๑) 2019 Korean Academy of Physical Therapy Rehabilitation Science 
strength [14,15], stability, deformity [16], and joint contracture [17] are digitized to evaluate before and after TKR [18].

According to advanced research, the decision making capabilities, satisfaction, and quality of life of patients may be the standard to determine patient condition [19]. Assessments for persons with TKR are actively being researched but most of them are functional assessments for surgeons.

Most evaluations of TKR assessments are centered on levels of body structure and function. There is also a lack of studies on the quality of life of persons with TKR, which can be used as clinical data. Thus, studies that include the life quality of TKR recipients based on opinion for assessment and development of TKR are insufficient. Therefore, this study evaluates the rehabilitation programs for persons with TKR and their social participation through the assessment of life quality related to TKR status and the period after operation.

\section{Methods}

One-hundred and thirty five subjects from Himchan Hospital in Seoul, South Korea, diagnosed with knee OA, were enrolled in this study. The subjects were provided with a full explanation of the experimental procedure, and provided written consent signifying voluntary participation. This study was approved by the Sahmyook University Human Studies Committee (SYUIRB2013-021). Patient demographic information is provided in Table 1. The detailed inclusion criteria are as follows: subjects were those who did not have other surgeries within 6 months, who did not have any functional limitations from neural or other diseases, and who fully understood and agreed with the research. The exclusion criteria were as follows: those who had other diseases diagnosed except for degenerative OA, who had reoperation less than 1 year after TKR [20], and who had uni-

Table 1. Characteristics of the participants

$(\mathrm{N}=135)$

\begin{tabular}{lrc}
\hline \multicolumn{1}{c}{ Variable } & $\begin{array}{c}\text { TKR group } \\
(\mathrm{n}=70)\end{array}$ & $\begin{array}{c}\text { Non TKR group } \\
(\mathrm{n}=65)\end{array}$ \\
\hline Age $(\mathrm{y})$ & $71.0(7.3)$ & $55.5(5.1)$ \\
Height $(\mathrm{cm})$ & $151.8(5.9)$ & $157.6(6.5)$ \\
Weight $(\mathrm{kg})$ & $62.8(9.0)$ & $67.6(9.1)$ \\
Body mass index $\left(\mathrm{kg} / \mathrm{m}^{2}\right)$ & $27.2(3.3)$ & $27.2(3.1)$ \\
\hline
\end{tabular}

Values are presented as mean (SD).

TKR: total knee replacement. compartmental knee replacement.

The subjects were randomized into a surgery group $(\mathrm{n}=70)$ and a non-surgery group $(\mathrm{n}=65)$. Their sex, age, weight, height, body mass index, unilateral or bilateral, and quality of life were evaluated. Change in quality of life was measured with the Short Form-36 Health Survey (SF-36). Seventy out of 135 patients had TKR surgery, and their quality of life was evaluated at 6 months and 12 months after the surgery.

The examiners for this study were researchers at $\mathrm{H}$ hospital research center and were fully informed of the objectives, backgrounds, record methods, and contents of the survey. The survey was conducted by the same examiner for every participant. Researchers explained the objectives and background of this study to the participants and had them sign on the survey if agreed. The investigation was conducted in the form of one-on-one question and answer sessions for the survey contents and the time spent collecting information was 20 minutes per person.

The quality of life was measured using the SF-36. The SF-36 is a commonly used generic health status questionnaire composed of eight subscales that measure physical functioning (PF), role physical (RP), bodily pain, general health (GH), vitality (VT), social function (SF), role limitations due to emotional problems (RE), and mental health (MH). The scores of each subscale are normalized to a scale ranging from 0 to 100 , with a higher score reflecting a better health status. SF-36 version 1 was used in this study [21].

All statistical analyses were performed using IBM SPSS Statistics for Windows, Version 19.0 (IBM Co., Armonk, NY, USA). The general characteristics are presented as mean and standard deviation values. The independent $t$-test was used for comparison of the quality of life for both groups. One-way repeated ANOVA was used for comparison of the SF-36 scores between 6 months and 12 months after the surgery. Results were considered significant at $p<0.05$.

\section{Results}

Comparison of quality of life between groups is shown in Table 2. There were significant differences in quality of life between the two groups of subjects with knee OA who had TKR surgery and those who did not $(p<0.05)$. Comparison of quality of life between 6 months and 12 months after the surgery is shown in Table 3 . SF-36 scores were significantly improved at 6 months and 12 months after the surgery compared to the scores before surgery $(p<0.05)$. Comparison be- 
tween 6 months and 12 months after surgery showed that the Vitality and Social Function score in the SF-36 increased significantly $(p<0.05)$.

\section{Discussion}

Shah et al. [22] compared the quality of life of subjects before and after total knee arthroplasty in clinical settings. The SF-36 results showed a significant $(p<0.05)$ improvement in health-related quality of life based on two subscales of the SF-36 (Physical Health Component and Mental Health Component) before surgery compared to after 6 months of surgery. Keurneties et al. [23] compared life quality between two groups that were distinguished by the severity of OA. The SF-36 PCS results showed that the slight OA group scored 1.5 and the severe OA group scored 6.4, indicating a considerable difference $(p<0.01)$. However, in other re-

Table 2. Comparison of quality of life between groups $(\mathrm{N}=135)$

\begin{tabular}{lcl}
\hline \multicolumn{1}{c}{ Variable } & $\begin{array}{c}\text { TKR group } \\
(\mathrm{n}=70)\end{array}$ & $\begin{array}{c}\text { Non TKR group } \\
(\mathrm{n}=65)\end{array}$ \\
\hline SF-36 & $43.3(3.5)$ & $46.7(4.7)^{* * *}$ \\
SF-36 PCS & $30.1(2.3)$ & $32.5(3.1)^{* * *}$ \\
SF-36 MCS & $38.8(1.0)$ & $39.2(1.6)^{*}$ \\
\hline
\end{tabular}

Values are presented as mean (SD).

TKR: total knee replacement, SF-36: short form-36 health survey, PCS: physical component summary, MCS: mental component summary. ${ }^{*} p<0.05,{ }^{* * *} p<0.001$. search, the slight OA group scored 0.1 and the severe group scored -0.3 in SF-36 mental component summary (MCS), which indicates no significant difference. Compared to these results, in the current study, the group that did not receive TKR scored 32.5 and those who had TKR operation scored 30.1 on the SF-36 PCS, therefore a significant difference was observed $(p<0.000)$. In a previous study, the groups who did not have TKR scored 39.2 while those who had TKR scored 38.8, with considerable differences $(p<0.046)$. Compared to the previous research, both studies had differences in PCS scores. However, only this study observed for difference in MCS scores. This is attributed to the gap between the influence of the physical factors and psychological factors of OA. Thus, TKR is considered to have a positive effect on physical activity when performed in severe stages of $\mathrm{OA}$.

Baker et al. [24] assessed the quality of life for TKR recipients before, 1 year after, and 3 years after the operation with the Western Ontario and McMaster Universities Osteoarthritis Index (WOMAC) and SF-36. The WOMAC score was increased from 39.9 before operation to 77.71 year after the operation. In this study, the score increased from 71.2 to 84.1. Both this study and the previous study showed remarkable differences between the quality of life before and 1 year after operation $(p<0.05)$. However, according to the previous research, there was no specific improvement from 1 year after and 3 years after the operation. This study observed minor differences between 6 months after and 12 months after

Table 3. Comparison of quality of life between 6 months and 12 months after the surgery

$(\mathrm{N}=70)$

\begin{tabular}{|c|c|c|c|c|c|}
\hline Variable & $\begin{array}{l}\text { Before the surgery } \\
\qquad(\mathrm{n}=70)\end{array}$ & $\begin{array}{l}6 \text { months after the } \\
\text { surgery }(n=62)\end{array}$ & $\begin{array}{l}12 \text { months after the } \\
\text { surgery }(n=37)\end{array}$ & $\mathrm{F}$ & Post hoc \\
\hline SF-36 & $43.3(3.5)$ & $59.3(6.0)$ & $60.7(7.1)$ & $178.92 *$ & $\mathrm{~B}, \mathrm{C}>\mathrm{A}$ \\
\hline PCS & $30.1(2.3)$ & $40.4(4.0)$ & $41.7(3.4)$ & $193.68^{*}$ & $\mathrm{~B}, \mathrm{C}>\mathrm{A}$ \\
\hline MCS & $38.8(1.0)$ & $45.6(2.8)$ & $46.3(3.0)$ & $118.04 *$ & $\mathrm{~B}, \mathrm{C}>\mathrm{A}$ \\
\hline PF & $42.9(10.0)$ & $58.0(9.6)$ & $60.8(7.2)$ & $56.05^{*}$ & $\mathrm{~B}, \mathrm{C}>\mathrm{A}$ \\
\hline $\mathrm{RP}$ & $0.0(<0.001)$ & $57.1(21.8)$ & $62.5(19.4)$ & $211.00^{*}$ & $\mathrm{~B}, \mathrm{C}>\mathrm{A}$ \\
\hline BP & $21.6(4.9)$ & $56.4(11.4)$ & $58.7(10.9)$ & $203.66^{*}$ & $\mathrm{~B}, \mathrm{C}>\mathrm{A}$ \\
\hline GH & $51.5(1.9)$ & $53.8(2.8)$ & $54.8(2.5)$ & $24.92 *$ & $\mathrm{~B}, \mathrm{C}>\mathrm{A}$ \\
\hline VT & 54.7 (1.9) & $64.3(4.1)$ & $66.5(4.2)$ & $114.33^{*}$ & $\mathrm{C}>\mathrm{B}>\mathrm{A}$ \\
\hline $\mathrm{SF}$ & $29.1(8.7)$ & $54.5(9.0)$ & $58.3(10.0)$ & $105.59^{*}$ & $\mathrm{C}>\mathrm{B}>\mathrm{A}$ \\
\hline $\mathrm{RE}$ & $0.0(<0.001)$ & $40.9(19.0)$ & $42.2(17.4)$ & $128.23 *$ & $\mathrm{~B}, \mathrm{C}>\mathrm{A}$ \\
\hline $\mathrm{MH}$ & $64.3(1.2)$ & $73.1(3.4)$ & $74.5(4.1)$ & $159.69^{*}$ & $\mathrm{~B}, \mathrm{C}>\mathrm{A}$ \\
\hline
\end{tabular}

Values are presented as mean (SD).

SF-36, short form-36 health survey, PCS: physical component summary, MCS: mental component summary, PF: physical function, RP: role physical, BP: bodily pain, GH: general health, VT: vitality, SF: social function, RE: role limitations due to emotional problems, MH: mental health.

${ }^{*} p<0.001$. 
the operation. This may be because the poor function of the knee joint was compensated, knee joint pain was reduced, and movement was smoothened by TKR in the early stages after the operation.

Stevens-Lapsley et al. [25] observed that the physical component summary (PCS) score increased from 36.7 to 49.26 months after the operation and MCS increased from 51.7 to 54.5 in a study involving 39 TKR subjects. These results indicated an improvement in SF-36. In this study, the PCS score was increased from 30.1 to 40.46 months after the operation, while MCS increased from 38.8 to 45.6, which is a remarkable increase $(p<0.05)$. Keureties et al. [23] studied the difference in life quality before and 2.82 years after the operation in TKR recipients through the SF-36. In advanced studies, with PF from 15.1 before $(p<0.001)$, GH and PCS showed considerable improvement $(p=0.01)$. In this study, VT and SF were considerably improved. This study showed overall improvements in life quality after the operation whereas the previous research showed only improvements in PCS. According to the results, due to biological limitations, the functional performance of patients is limited for up to 6 months after the operation [25]. This includes the possibility of improvement afterwards, and a potential decrease in biological limitations after 6 months. Improvements in physical items are considered to positively influence VT and SF, which are aspects of a patient's quality of life.

The limitations are the fact that the research data were obtained from patients from a single hospital, which limited the sample size. Additionally, it was difficult to explain the cause and effect relationship between persons with OA and the factors that affected them before the operation. Thus, since the investigation was a one-time event, it is hard to explain the relationship with variables. Another limitation could be the lack of assessment tools for muscle strength, which can influence the TKR.

The findings of this study showed that TKR surgery has a positive effect on the quality of life for knee OA patients as a therapeutic intervention. Efforts to improve the factors that affect quality of life are necessary and this topic is suggested for follow-up study.

\section{Conflict of Interest}

The authors declared no potential conflicts of interest with respect to the authorship and/or publication of this article.

\section{References}

1. Calatayud J, Casaña J, Ezzatvar Y, Jakobsen MD, Sundstrup E, Andersen LL. High-intensity preoperative training improves physical and functional recovery in the early post-operative periods after total knee arthroplasty: a randomized controlled trial. Knee Surg Sports Traumatol Arthrosc 2017;25:2864-72.

2. Allen KD, Golightly YM. State of the evidence. Curr Opin Rheumatol 2015;27:276-83.

3. Glyn-Jones S, Palmer AJ, Agricola R, Price AJ, Vincent TL, Weinans H, et al. Osteoarthritis. Lancet 2015;386:376-87.

4. Jahic D, Omerovic D, Tanovic AT, Dzankovic F, Campara MT. The effect of prehabilitation on postoperative outcome in patients following primary total knee arthroplasty. Med Arch 2018;72:439-43.

5. Noh EK, An CS. Changes in pain, swelling, and range of motion according to physical therapy intervention after total knee arthroplasty in elderly patients. Phys Ther Rehabil Sci 2015;4:79-86.

6. Kumagai K, Harigane K, Kusayama Y, Tezuka T, Inaba Y, Saito T. Total knee arthroplasty improves both knee function and disease activity in patients with rheumatoid arthritis. Mod Rheumatol 2017;27:806-10.

7. Holm B, Kristensen MT, Bencke J, Husted H, Kehlet H, Bandholm T. Loss of knee-extension strength is related to knee swelling after total knee arthroplasty. Arch Phys Med Rehabil 2010;91:17706.

8. Choi HS, Shin WS. Effects of game-based balance training with constraint-induced movement therapy on lower extremity function and balance confidence levels in women with total knee replacement. Phys Ther Rehabil Sci 2019;8:8-14.

9. Deakin AH, Smith MA, Wallace DT, Smith EJ, Sarungi M. Fulfilment of preoperative expectations and postoperative patient satisfaction after total knee replacement. A prospective analysis of 200 patients. Knee 2019. doi: 10.1016/j.knee.2019. 07.018. [Epub ahead of print]

10. Rosser RM, Watts VC. The measurement of hospital output. Int J Epidemiol 1972;1:361-8.

11. Rakel BA, Zimmerman MB, Geasland K, Embree J, Clark CR, Noiseux NO, et al. Transcutaneous electrical nerve stimulation for the control of pain during rehabilitation after total knee arthroplasty: A randomized, blinded, placebo-controlled trial. Pain 2014;155:2599-611.

12. Ewell M, Griffin C, Hull J. The use of focal knee joint cryotherapy to improve functional outcomes after total knee arthroplasty: review article. PM R 2014;6:729-38.

13. Harvey LA, Brosseau L, Herbert RD. Continuous passive motion following total knee arthroplasty in people with arthritis. Cochrane Database Syst Rev 2014;(2):CD004260.

14. Moyer R, Ikert K, Long K, Marsh J. The value of preoperative exercise and education for patients undergoing total hip and knee arthroplasty: a systematic review and meta-analysis. JBJS Rev 2017;5:e2.

15. Saleh KJ, Lee LW, Gandhi R, Ingersoll CD, Mahomed NN, Sheibani-Rad S, et al. Quadriceps strength in relation to total knee arthroplasty outcomes. Instr Course Lect 2010;59:119-30.

16. Su EP. Fixed flexion deformity and total knee arthroplasty. J Bone Joint Surg Br 2012;94(11 Suppl A):112-5.

17. Scuderi GR, Kochhar T. Management of flexion contracture in 
total knee arthroplasty. J Arthroplasty 2007;22(4 Suppl 1):20-4.

18. Coast J. Reprocessing data to form QALYs. BMJ 1992;305:8790.

19. Jayadev C, Khan T, Coulter A, Beard DJ, Price AJ. Patient decision aids in knee replacement surgery. Knee 2012;19:746-50.

20. Baumann C, Rat AC, Mainard D, Cuny C, Guillemin F. Importance of patient satisfaction with care in predicting osteoarthritisspecific health-related quality of life one year after total joint arthroplasty. Qual Life Res 2011;20:1581-8.

21. Ware JE Jr, Sherbourne CD. The MOS 36-item short-form health survey (SF-36). I. Conceptual framework and item selection. Med Care 1992;30:473-83.

22. Shah AMUD, Afzal F, Ans M, Ayaz S, Niazi SG, Asim M, et al. Quality of life before and after total knee arthroplasty in clinical settings across Lahore, Pakistan. Pak J Pharm Sci 2019;32(2
(Supplementary)):769-72.

23. Keurentjes JC, Fiocco M, So-Osman C, Onstenk R, KoopmanVan Gemert AW, Pöll RG, et al. Patients with severe radiographic osteoarthritis have a better prognosis in physical functioning after hip and knee replacement: a cohort-study. PLoS One 2013;8: e59500.

24. Baker P, Muthumayandi K, Gerrand C, Kleim B, Bettinson K, Deehan D. Influence of body mass index (BMI) on functional improvements at 3 years following total knee replacement: a retrospective cohort study. PLoS One 2013;8:e59079.

25. Stevens-Lapsley JE, Schenkman ML, Dayton MR. Comparison of self-reported knee injury and osteoarthritis outcome score to performance measures in patients after total knee arthroplasty. PM R 2011;3:541-9; quiz 9. 